Kansas State University Libraries

New Prairie Press

\title{
VARIATION ANALYSIS FOR FIBER QUALITY TRAITS AMONG DIFFERENT POSITIONSIN EIGHT UPLAND COTTON CULTIVARS
}

Yi Xu

Johnie N. Jenkins

Jack C. McCarty

Jixiang Wu

See next page for additional authors

Follow this and additional works at: https://newprairiepress.org/agstatconference

Part of the Agriculture Commons, and the Applied Statistics Commons

\section{(c) (1) $\Theta($}

This work is licensed under a Creative Commons Attribution-Noncommercial-No Derivative Works 4.0 License.

\section{Recommended Citation}

Xu, Yi; Jenkins, Johnie N.; McCarty, Jack C.; and Wu, Jixiang (2012). "VARIATION ANALYSIS FOR FIBER QUALITY TRAITS AMONG DIFFERENT POSITIONSIN EIGHT UPLAND COTTON CULTIVARS," Conference on Applied Statistics in Agriculture. https://doi.org/10.4148/2475-7772.1041

This is brought to you for free and open access by the Conferences at New Prairie Press. It has been accepted for inclusion in Conference on Applied Statistics in Agriculture by an authorized administrator of New Prairie Press. For more information, please contact cads@k-state.edu. 


\section{Author Information}

Yi Xu, Johnie N. Jenkins, Jack C. McCarty, and Jixiang Wu 


\title{
VariationAnalysis for Fiber Quality Traits among Different Positionsin Eight Upland Cotton Cultivars
}

\author{
Yi Xu ${ }^{1}$, Johnie N. Jenkins ${ }^{2}$, Jack C. McCarty ${ }^{2}$, Jixiang $\mathrm{Wu}^{1,3} \bowtie$ \\ 1.Plant ScienceDepartment, South Dakota State University, Brookings, SD 57007;2. Crop \\ Science Research Laboratory, USDA-ARS, Mississippi State, MS 39762; and 3. Department \\ of Mathematics and Statistics, South Dakota State University, Brookings, SD 57007. \\ 凶:Corresponding author: jixiang.wu@sdstate.edu
}

\begin{abstract}
Equivalencyof fiber quality within a plant of upland cotton, Gossypium hirsutum L., is very important. There are several traits within a plant that can be used to measure fiber quality and five of those traits will be investigated. Eight representative upland cultivars were grown at the Plant Science Research Farm at Mississippi State University in 1986 and five fiber traits: micronaire, fiber elongation, $2.5 \%$ and $50 \%$ span length, and fiber strength, were measured at different plant locations. The analysis of the study was modeled after a crop stability analysis with plant locations being treated as environments in the analysis. Three methodsof stability analyses were investigated:Francis and Kannenberg's (F-K), Finlay and Wilkinson's (F-W), and additive main effect and multiplication interaction (AMMI).The results showed that cultivar ST213 was stable for micronaire, MC235 for fiber span length, DPNSL and DES119for fiber elongation, and CAMD-E for fiber strength.
\end{abstract}

Key WordsVariation analysis; equivalency; upland cotton; fiber traits

\section{Introduction}

Cotton, which is the leading fiber crop and an important source of protein and oil in the world (An, Jenkins et al. 2010), has been planted in the United States for more than two centuries. The United Statesis the largest exporter of raw cotton, and cotton is animportant commodity throughout the world.Fiber quality of cotton has becomeincreasingly important to the textile industry due totechnology changes infiber spinning(Wu, Jenkins et al. 2009).It is well known that cotton fibers are collected from various positions on plants and the quality may vary. Equivalent fiber quality across a whole plant is highly desired by cotton breeders, producers, and marketers. It is important to know such important information for cultivars.

Genotypic-environment (GE) interaction is said to exist when the phenotypic response invoked by a change in environment is not the same for all genotypes (Comstock and Moll 1963). GE interaction is considered the index of stability. The stability of cultivars in different environments is an important application of plant breeding.Plant breeders are interested in selecting superior genotypes in the present of GE interaction(Francis and Kannenberg 1978).Several statistical methods for measuring stability were reported (Plaisted 
and Peterson 1959; Wricke 1962; Finlay and Wilkinson 1963; Eberhart and Russell 1966; Perkins and Jinks 1968; Shukla 1972; Francis and Kannenberg 1978). Among these,Francis and Kannenberg's (1978)(F-K) method, Finlay and Wilkinson’s (1963) (F-W) method, and Additive Main Effect and Multiplication Interaction (AMMI) analysis (Crossa, Gauch et al. 1990) were commonly used to analyze the stability of each crop cultivar to be released.

The above mentioned methods have been commonly used in crop yield stability analysis in crop trial tests but not forequivalent fiber quality across plant locations in cotton. It is reasonable to treateach location asan environment because they develop at different times and thus genotype-by-location interactions are equivalent to genotype-by-environment interactions. Therefore, the idea of stability of cultivars can be used to investigate the equivalency of fiber quality across different locations for each cultivar.

In this study, five fiber quality traits, micronaire(MIC), 50\% span length(50\%SL), $2.5 \%$ span length(2.5\%SL), elongation(E1), and strength(T1)collected by Knight (1988) were used for our analysis by F-K, F-Wand AMMI.The purpose ofthis study was to provide important information on fiber quality for cotton breeding, production, and marketing.

\section{Materials and Methods}

\subsection{Data Collection}

A collection of eight commercial cultivars was assembled from the Plant Science Research Farm at Mississippi State University in 1986. The cultivars were 'Stoneville 506'(ST506), 'Stoneville 213'(ST213), 'Stoneville 825'(ST825), 'Tamcot CAMD-E'(CAMD-E), 'DeltapineNectariless Smooth Leaf'(DPNSL), 'Deltapine 50'(DPL50), 'McNair 235'(MC235), and 'DES 119'(DES119),these were designated as G1- G8 for analysis.

More details about the data and experiments can be found in Knight's thesis (Knight 1988).After cotton had matured, a random 10 foot strip of each plot was harvested, by position from each plot. The mapping consisted of removing each boll separately from plants and placing it in a paper bag with the appropriate horizontal position and vertical node number recorded. Bolls were composited by position for all plants in the 10 foot strip. The samples were taken to the laboratory, and allowed to dry and then weighted to determine seed cotton weight. In this study, interest was in fiber quality traits which included micronaire(MIC), 50\% span length(50\%SL), 2.5\% span length(2.5\%SL), elongation(E1), and strength(T1). Micronaire is the fineness of the sample taken from the ginned lint, measured by the micronaire and expressed in standard (curvilinear scale) micronaire units.The 50\% SL is the length in millimeters on the test specimen spanned by 50 percent of the fibers scanned at the initial starting point. The $2.5 \%$ SL measures the length in millimeters that $2.5 \%$ of the fibers span from initial starting point. Fiber strength is expressed as T1, which is the strength of a bundle of fibers measured on the Stelometer, an instrument for measuring fiber strength, with two jaws holding the fiber bundle separated by a 1/8-inch spacer, expressed in millinewtons $(\mathrm{mN} / \mathrm{kg})$. E1 is the percent elongation at the break of the center one-eighth inch of the fiber bundle measured by strength(Knight 1988). 
Normally, the number of main-stem nodes on a plant are counted from bottom to top to number the branches.In this study, the branches numbered from 8 to 17 were investigated.The cotton bolls on each branch were termed as position. The nearest boll to the main-stem was designated position one, and the one next to it was position two,andbeyond that was considered three. However, position threewas not investigated in this study due to many missing data points. For clarification, locationin this study was defined as the combination of position and node. For example, position oneon the $10^{\text {th }}$ node was designated as “ 10.1 ".

\subsection{Statistical Analysis}

We investigated the equivalency of a trait in several ways so that more complete information may be obtained. The first method used was Francis and Kannenberg's (1978) method, which is a two-way ANOVA model detailed as follows:

$y_{i j}=\mu+G_{i}+P_{j}+P G_{i j}+e_{i j}$

where $y_{i j}$ is the observation for genotype $i$ in position $j ; \mu$ is the population mean; $G_{i}$ is the mean of the $i^{t h}$ genotypic effect; $P_{j}$ is the mean of the $j^{\text {th }}$ positional effect; $P G_{i j}$ is the interaction and $e_{i j}$ is the residual.The last two terms are confounded and cannot be separated if only based on mean values over replications/blocks. In order to demonstrate several methods used in this study, we also defined $\bar{y}_{i}, \bar{y}_{\cdot j}$, and $\bar{y}$ as the mean values for the $i^{\text {th }}$ genotype, the $j^{\text {th }}$ position, and the population mean, respectively.With this model,the coefficient of variability $\left(C V_{i}\right)$ of each genotype was used as a stability measure(Lin, Binns et al. 1986), i.e.

$C V_{i}=\frac{S_{i}}{\bar{y}_{i}} \times 100$

where $S_{i}^{2}=\frac{\sum_{j=1}^{q}\left(y_{i j}-\bar{y}_{i}\right)^{2}}{q-1}$.

The second method was Finlay and Wilkinson's (1963) regression method. With this method,the observations of each genotype were regressed on position indexes (PI), which were the mean value of observationsfor all positions. The regression coefficient $b_{i}$ was defined as follows(Lin, Binns et al. 1986):

$b_{i}=\frac{\sum_{j=1}^{q}\left(y_{i j}-\bar{y}_{i} \cdot\right)\left(\bar{y}_{\cdot j}-\bar{y}\right)}{\sum_{j=1}^{q}\left(\bar{y}_{\cdot j}-\bar{y}\right)^{2}}(3)$

The third methodwas the Additive Main Effect and Multiplication Interaction (AMMI) method(Crossa, Gauch et al. 1990), which is based on a principal component (PC) analysis. The AMMI model is:

$y_{i j}=\mu+G_{i}+P_{j}+\sum_{k=1}^{n} \lambda_{k} \alpha_{i k} \gamma_{j k}+e_{i j}(4)$

where $\mu, y_{i j}, G_{i}$ and $P_{j}$ were defined in equation (1) above. $\lambda_{k}$ is the square root of the eigenvalue of the PC axisk; $\alpha_{i k}$ and $\gamma_{j k}$ are the PC scores for PC axiskof the $i^{\text {th }}$ genotype and the $j^{t h}$ position, respectively,and $e_{i j}$ is the residual. In model (4), genotype-by-position interaction was subdivided into PC scores(Crossa, Gauch et al. 1990).

Data were analyzed by the three methods using R programs.The following libraries were mainly used in this study:GenMod, MASS, agricolae, MEMSS, lattice,plotrix (See appendix). 


\section{Results and Discussion}

\subsection{Coefficient of variation}

In F-K method, coefficient of variation (CV)wasused as a measure of consistency for a cultivarregarding these traits across different positionson the condition that a cultivar will have a larger variance(Lin, Binns et al. 1986). Mean traits were plotted against their corresponding CVs in Figure 1. Based onmean CV andpopulation mean trait,four groups can be observed:Group 1 (high mean with small variation), Group 2(high mean with large variation), Group 3 (low mean with small variation), and Group 4 (low mean with large variation).

Low value of micronaire means finer fibers while high mean values are more desired for the other four traits.In addition, small variation means more stable and thus is more desired for all five traits. According to the definition of stable genotype which provides high (or low, for example MIC) and consistent performance(Francis and Kannenberg 1978), group 3 for micronaire and group 1 for other fiber traits can be considered as stable and thus more desirable. For micronaire(MIC),ST213 (G2)and DPNSL (G5) had better performance; for 50\%SL onlyMC235 (G7) had better performance; for 2.5\%SLDPL50 (G6), MC235 (G7) and DES119 (G8) had better performance; for elongation, ST506 (G1), DPNSL (G5)and DES119 (G8) had better performance; for strength, onlyCAMD-E (G4) had better performance (Figure1).

\subsection{Regression analysis}

In F-W method, the simple regression between a trait mean and its corresponding positionindex (PI) for five traits was used in this study(Lin, Binns et al. 1986). Coefficient of determination $\left(\mathrm{R}^{2}\right)$ was considered the measurement of the consistent of a genotype on position index. The value of $\mathrm{R}^{2}$ is closeto 1suggeststhat a cultivar has a high consistenceto the mean performance of other cultivars. The value of a slope greater than one means above average stability while a value smaller than one means below average stability, and a value equal to one means it is equal to the average stability (Finlay and Wilkinson 1963). All results are summarized Table 1.

For micronaire, ST506 (G1), ST825 (G3),CAMD-E (G4) and MC235 (G7) had high consistence and better performance in good position conditions(b1>1, R2>0.70); for 50\% span length, DPNSL (G5) and DPL50 (G6) had high consistence and better performance in good position conditions(b1>1, R2>0.70)(Table 1).

Mean traits are plotted against their corresponding simple regression coefficientsin Figure2, respectively. Mean simple regression coefficient and populationmean trait divide every figure into four groups according to high or low trait value and large or small slope. For micronaire, 50\% span length and strength, the results showed in Figure 2were the same as the results of F-K method.

\subsection{AMMI analysis}

Additive main effects and multiplicative interaction (AMMI) analysis of variance(Crossa, Gauch et al. 1990) showed that the first two principal component (PC) scores contributed to 
$63.9 \%, 63.3 \%$, $88.5 \%, 56 \%$, and56.2\% of total variation of genotype-by-position interaction effects for traits MIC, 50\%SL, 2.5\%SL, E1 and T1, respectively. However, only the first PC score weresignificant at the probability level of 0.05 .

With this method, we selected micronaire for analysisdue to the page limits, and the results of other fiber traits will be summarized in Tables 3 and 4. Figure 3is a bi-plot generated for the first principal component (PC1) scores as the abscissas and the second principal component (PC2)scores as the ordinates for trait micronaire. Genotypes (or locations) that appear almost on perpendicular lineand/or those that fall almost on a horizontal line are considered having similar interaction patterns(Crossa, Gauch et al. 1990).Genotypes (or locations) with high PCscores (either positive or negative) may have high interactions. A cultivar with PC1 and PC2 scores close to the origin $(0,0)$ suggests that this cultivar had small genotype-by-location interaction and thus more stable.

For micronaire, ST213 (G2), MC235 (G7) and most locations close to (0,0), and DPL50 (G6), these werestable on the condition that only PC1 scorewas considered (Figure 3).Variations between cultivars were more significant than variations between locations. Location 17.2 was the farthest point in the figure which means it was not stable.Low micronaire means finer fibers and thus is more desired. Cultivars ST506 (G1), ST213 (G2), ST825 (G3) and DPNSL (G5) had smaller values of micronaire than the average mean (3.16). Means of positionone were greater than means of positiontwo for every branch while most means of postionone were greater than means of postiontwo for whole cotton plant. All means for two positions of 10 nodes in five traitsare listed in Table 2.Fruit in branch position one developed more completely than fruit in branch position two. In this analysis, means were compared for each of two branch locations. At branch position one,locations 12.1, 13.1, 14.1 15.1, 16.1 and 17.1 were below the average mean of branch positionone (3.27), whereas at branch position two, locations 15.2, 16.2 and 17.2 were below the average mean of branch positiontwo (3.06) (Table 2).Thuscultivar ST213 (G2)and locations 15.2, 16.2, 12.1, 13.1, 14.1, 15.1, 16.1, 17.1had better performance regarding micronaire. High mean values are more desired for the other four traits. Similarly, cultivars and/orlocations with better performance could be observed in Tables 3 and 4 .

\section{Summary}

The techniques of the three methods used in the analysis of the study are different (Lin et al., 1986); however; as given in Table 3, the results obtained by the three methods are comparable. ST213 (for micronaire), MC235 (for 50\% span length),MC235 (for 2.5\% span length),DPNSL and DES119 (for elongation), and CAMD-E (for strength) had better performance.As we expected, some differences among the three methods were observed. For example, cultivar DPNSLhad better performance for micronaire based on the F-W method and F-K method;DPL50 had better performance for 50\% fiber span length based on the AMMI analysis;DPL50 and DES119 had better performancefor elongation based on the F-K method andAMMI analysis; DPL50 has better performance for elongation based on the F-W method. In addition to the results obtained from the three proposed methods in this study, we 
analyzed the two factor interactions and no significant interaction effects were detected. On the other hand, the AMMI approach detected the first PC scores were significant, indicating that the AMMI method is more sensitive to detect interaction effects. We plan to validate them by simulated data in the future.

\section{Appendix}

Links to program R packages:

- MASS: http://cran.r-project.org/web/packages/MASS/index.html

- agricolae: http://tarwi.lamolina.edu.pe/ fmendiburu/

- MEMSS: http://cran.r-project.org/web/packages/MEMSS/index.html

- lattice: http://lattice.r-forge.r-project.org/

- plotrix: http://cran.r-project.org/web/packages/plotrix/index.html

\section{References}

An, C. , J. N. Jenkins, et al. (2010). "Use of fiber and fuzz mutants to detect QTL for yield components, seed, and fiber traits of upland cotton." Euphytica172(1): 21-34.

Comstock, R. E. and R. H. Moll (1963). Genotype-environment interactions, Nat. Acad. Sci.-Nat' Res. Counc' Publ.

Crossa, J., H. G. Gauch, et al. (1990). "Additive Main Effects and Multiplicative Interaction Analysis of Two International Maize Cultivar Trials." Crop Science30(3): 493-500.

Eberhart, S. A. and W. A. Russell (1966). "Stability parameters for comparing verirties." Crop Science6: 36-40.

Finlay, K. W. and G. N. Wilkinson (1963). "The analysis of adaptation in a plant-breeding programme." Aust. J. Agric. Res.14: 742-752.

Francis, T. R. and L. W. Kannenberg (1978). "Yield stability studies in short season maize. I. A descriptive method for grouping genotypes." Can. J. Plant Sci.58: 1029-1034.

Knight, B. L. (1988). Effects of fruiting position on yield and fiber quality in cotton. Deapartment of Agronomy. Mississippi, Mississippi State University. Master of Science.

Lin, C. S., M. R. Binns, et al. (1986). "Stability analysis: where do we stand?" Crop Science26: 894-899.

Perkins, J. M. and J. L. Jinks (1968). "Environmental and genotype-environmental components of variability. III. Multiple lines and crosses." Heredity23: 339-356. 
Plaisted, R. L. and L. C. Peterson (1959). "A technique for evaluating the ability of selections to yield consistently in different locations or seasons." Amer. Potato J.36: 381-385.

Shukla, C. K. (1972). "Some statistical aspects of partitioning genotype-environmental components of variability." Heredity29: 237-245.

Wricke, G. (1962). "Uber eine Methode zur Erfassung der okologischen Streubreite in Feldversuchen." Z. Pflanzenzuchtg47: 92-96.

Wu, J. , J. N. Jenkins, et al. (2009). "Seed trait evaluation of Gossypium barbadense L. chromosomes/arms in a G-hirsutum L. background." Euphytica167(3): 371-380. 


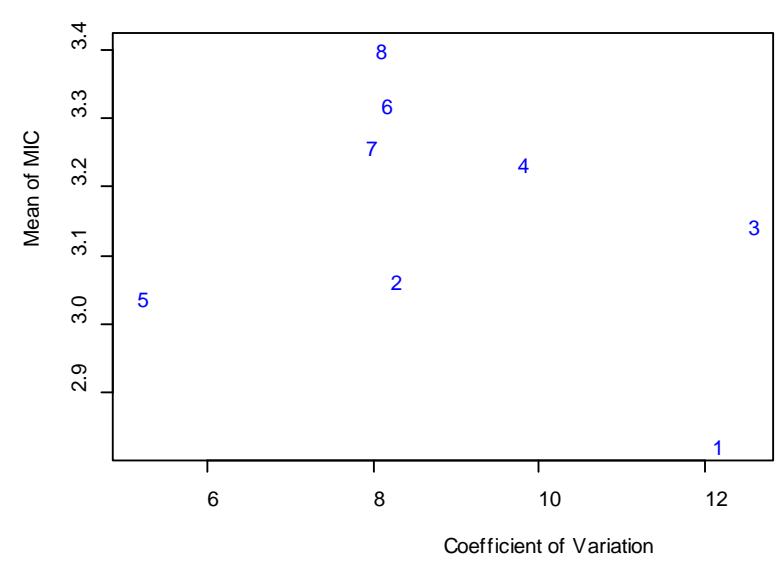

Figure 1 Means and Coefficients of Variation (CVs) for eight cultivars and five fiber traits 1=ST506, 2=ST213, 3=ST825, 4=CAMD-E, 5=DPNSL, 6=DPL50, 7=MC235, 8=DES119. 
Table 1 Slope and $\mathrm{R}^{2}$ Values for eight Cultivars by Bootstrapping Test ${ }^{\dagger}$

\begin{tabular}{|c|c|c|c|c|c|c|c|c|c|}
\hline \multirow[t]{2}{*}{ Trait $^{\ddagger}$} & \multirow[t]{2}{*}{ Cultivar } & \multicolumn{4}{|c|}{ Slope } & \multicolumn{4}{|c|}{$\mathrm{R}^{2}$} \\
\hline & & Orig & Boot & LL & UL & Orig & Boot & LL & UL \\
\hline \multirow[t]{8}{*}{ MIC } & ST506 & 1.370 & 1.410 & 1.031 & 1.978 & 0.785 & 0.797 & 0.642 & 0.893 \\
\hline & ST213 & 0.945 & 0.941 & 0.538 & 1.324 & 0.686 & 0.667 & 0.303 & 0.860 \\
\hline & ST825 & 1.638 & 1.679 & 1.377 & 2.065 & 0.843 & 0.842 & 0.703 & 0.933 \\
\hline & CAMD-E & 1.241 & 1.251 & 1.063 & 1.460 & 0.757 & 0.743 & 0.439 & 0.921 \\
\hline & DPNSL & 0.317 & 0.309 & -0.067 & 0.630 & 0.199 & 0.234 & 0.002 & 0.642 \\
\hline & DPL50 & 0.813 & 0.829 & 0.270 & 1.388 & 0.446 & 0.446 & 0.088 & 0.692 \\
\hline & MC235 & 1.037 & 1.010 & 0.705 & 1.222 & 0.785 & 0.757 & 0.456 & 0.925 \\
\hline & DES119 & 0.638 & 0.569 & -0.307 & 1.217 & 0.266 & 0.305 & 0.001 & 0.797 \\
\hline \multirow[t]{8}{*}{$50 \% S L$} & ST506 & 0.747 & 0.738 & 0.360 & 1.071 & 0.491 & 0.485 & 0.139 & 0.751 \\
\hline & ST213 & 0.549 & 0.562 & 0.178 & 1.008 & 0.352 & 0.373 & 0.067 & 0.722 \\
\hline & ST825 & 1.139 & 1.121 & 0.723 & 1.577 & 0.638 & 0.645 & 0.375 & 0.849 \\
\hline & CAMD-E & 0.762 & 0.729 & 0.040 & 1.170 & 0.281 & 0.314 & 0.006 & 0.715 \\
\hline & DPNSL & 1.280 & 1.287 & 0.921 & 1.657 & 0.765 & 0.766 & 0.599 & 0.892 \\
\hline & DPL50 & 1.687 & 1.688 & 1.155 & 2.272 & 0.706 & 0.716 & 0.483 & 0.890 \\
\hline & MC235 & 0.657 & 0.672 & 0.070 & 1.210 & 0.329 & 0.378 & 0.009 & 0.813 \\
\hline & DES119 & 1.178 & 1.204 & 0.605 & 1.858 & 0.506 & 0.515 & 0.254 & 0.772 \\
\hline \multirow[t]{8}{*}{$2.5 \% \mathrm{SL}$} & ST506 & 2.777 & 2.679 & 0.567 & 5.623 & 0.324 & 0.449 & 0.260 & 0.749 \\
\hline & ST213 & 0.875 & 0.904 & 0.294 & 1.430 & 0.509 & 0.553 & 0.099 & 0.896 \\
\hline & ST825 & 0.603 & 0.617 & 0.058 & 1.082 & 0.345 & 0.396 & 0.009 & 0.793 \\
\hline & CAMD-E & 0.342 & 0.358 & 0.025 & 0.769 & 0.165 & 0.195 & 0.004 & 0.481 \\
\hline & DPNSL & 0.885 & 0.916 & 0.309 & 1.479 & 0.383 & 0.409 & 0.063 & 0.778 \\
\hline & DPL50 & 1.089 & 1.114 & 0.398 & 1.751 & 0.533 & 0.572 & 0.119 & 0.917 \\
\hline & MC235 & 0.321 & 0.350 & -0.319 & 1.066 & 0.067 & 0.178 & 0.000 & 0.697 \\
\hline & DES119 & 1.108 & 1.137 & 0.583 & 1.708 & 0.465 & 0.489 & 0.164 & 0.844 \\
\hline \multirow[t]{8}{*}{ E1 } & ST506 & 0.990 & 0.982 & 0.468 & 1.432 & 0.425 & 0.427 & 0.137 & 0.677 \\
\hline & ST213 & 1.740 & 1.762 & 1.240 & 2.396 & 0.540 & 0.545 & 0.298 & 0.763 \\
\hline & ST825 & 1.107 & 1.133 & 0.753 & 1.565 & 0.551 & 0.558 & 0.259 & 0.795 \\
\hline & CAMD-E & 0.966 & 0.994 & 0.085 & 2.079 & 0.250 & 0.279 & 0.008 & 0.594 \\
\hline & DPNSL & 0.730 & 0.704 & 0.164 & 1.095 & 0.347 & 0.352 & 0.018 & 0.699 \\
\hline & DPL50 & 0.545 & 0.502 & -0.305 & 1.067 & 0.076 & 0.128 & 0.001 & 0.470 \\
\hline & MC235 & 1.259 & 1.233 & 0.255 & 2.102 & 0.400 & 0.409 & 0.040 & 0.717 \\
\hline & DES119 & 0.662 & 0.697 & 0.213 & 1.336 & 0.230 & 0.255 & 0.039 & 0.552 \\
\hline \multirow[t]{8}{*}{$\mathrm{T} 1$} & ST506 & 1.283 & 1.330 & 1.035 & 1.936 & 0.655 & 0.651 & 0.436 & 0.816 \\
\hline & ST213 & 0.107 & 0.032 & -1.004 & 0.462 & 0.010 & 0.152 & 0.000 & 0.583 \\
\hline & ST825 & 0.471 & 0.519 & 0.189 & 1.049 & 0.172 & 0.196 & 0.038 & 0.409 \\
\hline & CAMD-E & 0.920 & 0.846 & -0.105 & 1.504 & 0.354 & 0.350 & 0.004 & 0.716 \\
\hline & DPNSL & 1.067 & 1.145 & 0.644 & 2.123 & 0.462 & 0.491 & 0.241 & 0.723 \\
\hline & DPL50 & 1.554 & 1.586 & 1.124 & 2.201 & 0.525 & 0.540 & 0.248 & 0.817 \\
\hline & MC235 & 1.237 & 1.220 & 0.690 & 1.681 & 0.463 & 0.461 & 0.129 & 0.757 \\
\hline & DES119 & 1.361 & 1.306 & 0.734 & 1.708 & 0.547 & 0.521 & 0.120 & 0.797 \\
\hline
\end{tabular}




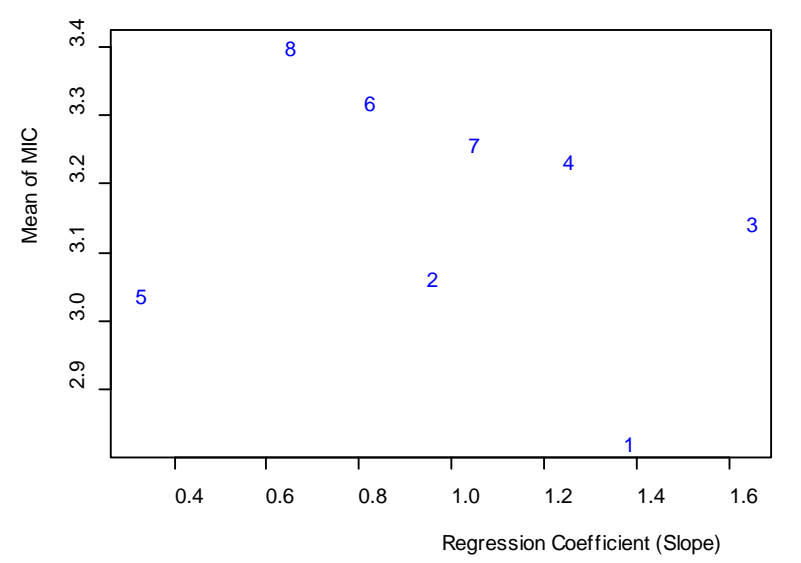

Figure 2 Means and Regression Coefficients for eight cultivars and five fibertraits 1=ST506, 2=ST213, 3=ST825, 4=CAMD-E, 5=DPNSL, 6=DPL50, 7=MC235, 8=DES119. 


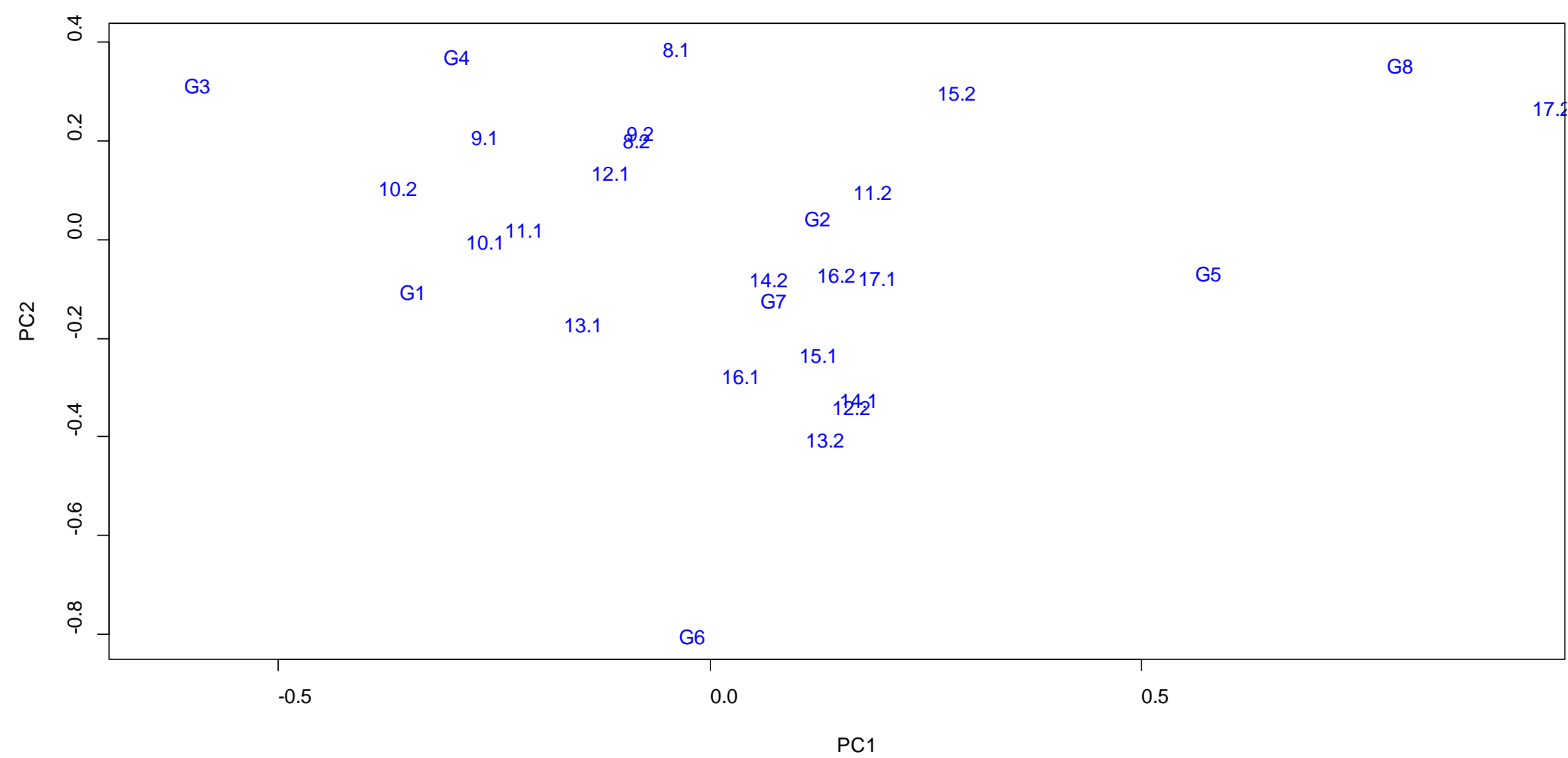

Figure 3 Results of Bi-Plot Graphics with the first principal component (PC1) and the second principal component (PC2) scores for MIC G1=ST506, G2=ST213, G3=ST825, G4=CAMD-E, G5=DPNSL, G6=DPL50, G7=MC235, G8=DES119. 
Table 2 Means for two positions10 nodes andfive fiber traits

\begin{tabular}{|c|c|c|c|c|c|c|c|c|c|c|}
\hline & \multicolumn{10}{|c|}{ Traits $^{\dagger}$} \\
\hline & \multicolumn{2}{|c|}{ MIC } & \multicolumn{2}{|c|}{$50 \%$ SL } & \multicolumn{2}{|c|}{$2.5 \% \mathrm{SL}$} & \multicolumn{2}{|c|}{ E1 } & \multicolumn{2}{|c|}{$\mathrm{T} 1$} \\
\hline Node & 1 & 2 & 1 & 2 & 1 & 2 & 1 & 2 & 1 & 2 \\
\hline 8 & 3.74 & 3.38 & 12.48 & 12.23 & 28.36 & 28.10 & 7.05 & 7.55 & 172.5 & 180.1 \\
\hline 9 & 3.50 & 3.15 & 12.44 & 12.66 & 28.39 & 28.53 & 7.21 & 7.45 & 176.3 & 179.1 \\
\hline 10 & 3.36 & 3.13 & 12.61 & 12.58 & 28.70 & 28.83 & 7.40 & 7.45 & 178.9 & 179.9 \\
\hline 11 & 3.31 & 3.09 & 12.99 & 12.71 & 28.95 & 29.21 & 7.36 & 7.68 & 181.4 & 182.4 \\
\hline 12 & 3.25 & 3.08 & 12.89 & 12.71 & 29.04 & 27.94 & 7.69 & 7.64 & 183.2 & 181.7 \\
\hline 13 & 3.15 & 3.13 & 13.01 & 12.71 & 29.34 & 29.04 & 7.60 & 7.84 & 183.3 & 178.0 \\
\hline 14 & 3.16 & 3.09 & 13.06 & 12.73 & 29.40 & 28.94 & 7.83 & 7.71 & 181.1 & 172.7 \\
\hline 15 & 3.08 & 2.89 & 13.01 & 12.36 & 29.29 & 28.35 & 7.75 & 7.93 & 179.3 & 177.0 \\
\hline 16 & 3.13 & 2.85 & 12.80 & 12.50 & 29.05 & 28.60 & 7.61 & 7.86 & 177.1 & 180.4 \\
\hline 17 & 2.99 & 2.80 & 12.64 & 12.20 & 28.63 & 28.06 & 7.83 & 7.94 & 172.5 & 180.1 \\
\hline Average & 3.27 & 3.06 & 12.79 & 12.54 & 28.92 & 28.56 & 7.53 & 7.71 & 178.6 & 179.1 \\
\hline
\end{tabular}

${ }^{\dagger} \mathrm{MIC}=$ micronaire, $50 \% \mathrm{SL}=50 \%$ span length, $2.5 \% \mathrm{SL}=2.5 \%$ span length, E1=elongation, and $\mathrm{T} 1=$ strength.

Table 3 Results forcultivars ${ }^{\dagger}$ and five fiber traits ${ }^{\ddagger}$ using three methods for stability

\begin{tabular}{cccccc}
\hline Method & MIC & 50\%SL & 2.5\%SL & E1 & T1 \\
\hline Francis and Kannenberg (1978) & G2,G5 & G7 & G6,G7,G8 & G5,G8 & G4 \\
Finlay and Wilkinson (1963) & G2,G5 & G7 & G7 & G5,G6,G8 & G4 \\
Crossa et al. (AMMI, 1990) & G2 & G6,G7 & G6,G7,G8 & G5,G8 & G4 \\
\hline
\end{tabular}

${ }^{\dagger} \mathrm{G} 1=\mathrm{ST} 506, \mathrm{G} 2=\mathrm{ST} 213$, G3=ST825, G4=CAMD-E, G5=DPNSL, G6=DPL50, G7=MC235, G8=DES119.

${ }^{\ddagger} \mathrm{MIC}=$ micronaire, $50 \% \mathrm{SL}=50 \%$ span length, $2.5 \% \mathrm{SL}=2.5 \%$ span length, $\mathrm{E} 1=$ elongation, and $\mathrm{T} 1=$ strength.

Table 4 Results of detecting positions by $\mathrm{AMMI}^{\dagger}$ analysis for five fiber traits ${ }^{\ddagger}$

\begin{tabular}{cccccc}
\hline Branch position & MIC & $50 \%$ SL & $2.5 \%$ SL & E1 & T1 \\
\hline 1 & $12.1,13.1$, & $11.1,12.1$, & $11.1,12.1$, & $13.1,14.1$, & $10.1,11.1$, \\
& $14.1,15.1$, & $13.1,14.1$, & $13.1,14.1$, & $15.1,16.1$ & $12.1,13.1$, \\
& $16.1,17.1$ & $15.1,16.1$ & 15.1 & & $14.1,15.1$ \\
\hline 2 & $15.2,16.2$ & $10.2,11.2$, & $11.2,13.2$, & $13.2,14.2$, & $8.2,10.2$, \\
& & 14.2 & 16.2 & 16.2 & $11.2,12.2$, \\
& & & & & 16.2 \\
\hline
\end{tabular}

${ }^{\dagger}$ AMMI=Additive Main Effect and Multiplication Interaction analysis

${ }^{\ddagger} \mathrm{MIC}=$ micronaire, 50\%SL=50\% span length, 2.5\%SL=2.5\% span length, E1=elongation, and T1=strength. 